\title{
Response Strategy and Scenarios for Accidents in Crude Oil and Gas Pipelines
}

\author{
Huseyin Murat Cekirge \\ Department of Mechanical Engineering, the Grove School of Engineering, the City College of the City University of New York, New York, \\ USA
}

\section{Email address: \\ hmcekirge@usa.net}

\section{To cite this article:}

Huseyin Murat Cekirge. Response Strategy and Scenarios for Accidents in Crude Oil and Gas Pipelines. International Journal of Environmental Monitoring and Analysis. Special Issue: Environmental Social Impact Assessment (ESIA) and Risk Assessment of Crude Oil and Gas Pipelines. Vol. 3, No. 6-1, 2015, pp. 18-25. doi: 10.11648/j.ijema.s.2015030601.13

\begin{abstract}
This paper introduces response scenarios used for spill training, planning, and real time oil spill response to be utilized for mitigation of spill accidents. A series of scenarios with the response guidelines and strategies are presented during accidents of crude oil and natural gas (NG) and natural gas liquids (NGL) pipelines.
\end{abstract}

Keywords: Accident Scenarios for Hydrocarbon Pipelines, Risk Scenarios, Strategies for Accidents of Crude Oil Pipelines, Strategies for Accidents of NG and NGL Pipelines

\section{Introduction}

The response scenarios for accidents happening hydrocarbon systems are important part of planning, training and real time mitigation plans of hydrocarbon pipeline systems. Each system has own properties and its special situation during the accidents. In the study, sample scenarios and its necessary elements will be introduced, and that will a starting point for real-like and appropriate accident scenarios.

As it is consistent across the entire Pipeline System, the Operating Company as an Operator has adopted the internationally recognized three-tiered approach for classification of oil spills in the design of its oil spill response capability. For each tier, a planning volume has been established which corresponds to a volume that can reasonably be expected for the pipeline in the area. Tier descriptions, and their corresponding planning volumes are summarized as follows for off-shore and on-shore spills.

Tier 1: Minor Spills

Tier 1 includes small operational spills which can be responded to by local personnel. Based on the most probable spill size, the Pipeline General Oil Spill Plans may set a planning volume of approximately $500 \mathrm{~m}^{3}$ for pipelines and approximately $300 \mathrm{~m}^{3}$ for marine spills.

Tier 2: Major Spills

Tier 2 includes incidents that can be responded to with in-country resources. The planning guideline volume for Tier 2 pipeline spills is are based on the Quantified Risk
Assessment Report which identifies environmental risk associated with different pipeline failure modes and with the highest environmental risk (based on possible spill volume, and potential frequency) associated with pipeline holes (50 $\mathrm{mm}$ ) caused by third party accidents. Based on these numbers, the Tier 2 spill planning guideline volume of approximately $3000 \mathrm{~m}^{3}$ has been adopted for pipeline spills in the pipeline area. For marine spills, the Pipeline General Oil Spill Plans may set the Tier 2 value at $2,000 \mathrm{~m}^{3} ; 1 \mathrm{~m} 3$ is considered to be approximately equal to $1 \mathrm{t}$. It is important to recognize that in actual practice, the Tier 2 volume will be determined by incident-specific parameters and may differ from this planning volume.

Tier 3: Crisis Event

Tier 3 requires augmenting in-country resources with assets from other countries. Although extremely unlikely, a Tier 3 incident will most likely result from a full bore rupture of the pipeline or a tanker collision/grounding. The Pipeline General Oil Spill Plans may set the Tier 3 planning value around $100,000 \mathrm{~m}^{3}$ for a marine related incident. The Tier 3 planning volume may not set for land pipeline spills in the Pipeline Company's General Oil Spill Plan, although the average calculated full-bore rupture loss is approximately $6000 \mathrm{~m}^{3}$.

A rapid response is essential in the containment and control of an oil spill. The Operating Company has structured its response capability to meet Response Time Planning Guidelines, which cover from spill notification, through mobilization of initial resources and their arrival at 
deployment locations, and the time to deploy Tier 2 Full Capability resources, if needed. The Operating Company has trained emergency response personnel contactable by telephone, pager and/or radio on standby 24 hours a day, 365 days a year.

Response time planning guidelines are summarized in Table 1 and are consistent across the entire Pipeline System. For each response depot, a mobilization planning time of 2 hours is anticipated for initial responders to report to an assigned response base. Response equipment located at a response base will be stored and maintained to allow for a planned departure time from a response base within 2 hours of arrival of personnel. Response depots are located within 4 hours driving time of any control point under daylight and clear weather conditions. Delays due to snow or other adverse conditions are unpredictable and cannot be provided for in these response time planning guidelines.

Table 1. Pipeline response time guidelines.

\begin{tabular}{llc}
\hline Activity & Response Time (hr) & Cumulative (hr) \\
\hline Notification & 0 & 0 \\
Mobilization at Response Depot & 2 & 2 \\
Departure from Response Depot with appropriate equipment & 2 & 4 \\
Travel time to spill site & 4 & 8 \\
Deployment of initial response resources at spill site & 4 & 12 \\
Tier 2 Full Capability in place using equipment and resources from other response bases & 12 \\
\hline
\end{tabular}

Considering the size and complexity of the pipeline area as well as logistical factors, response depots must be established to meet the response planning guidelines. The location and number of the response depots are depending on response time and pipeline characteristics. It should be noted that airport with access to these depots is very important in the case Tier 3 spills. The airports should facilitate landing of large plane that will carry heavy response equipment. The location of equipment depot requires detailed analysis for optimum response, the equipment and and personnel stationed in these depots must be determined according to a detailed analysis of whole pipeline, surrounding environment and containment sites, [1 - 4].

\subsection{Response Strategy On-Shore Spills}

The oil spill response strategy considers a Tiered response, beginning with the ability to handle the spill with on-site personnel (Tier 1), progressing to a Tier 2 spill utilizing resources internal to the Operating Company and the area, and extending to Tier 3 when additional (external) resources are needed.

The strategy to respond to land-based spills utilizes the following components that are in place along the pipeline:

- Establishment of a Tier 1 capability and appropriate spill response kits at each facility including Personal Safety Equipments (PPE);

- Placement of response kits on each truck coming to a facility;

- Employment of a Response Contractor to provide 24-hour Tier 2 response capability for the pipeline and terminal system;

- Participation in an international Tier 3 response organization;

- Identification of minimally two downstream Containment Sites for the capture and recovery of potential oil spills from each one-kilometer segment of pipeline;

- Establishment of a number of response depots designed to meet planning transit time guidelines discussed previously;

- Selection of equipment to meet the following time, spill volume recovery, and storage guidelines, $1 \mathrm{~m}^{3}=\sim 1 \mathrm{t}$ :

- Less than 12 hours for the deployment of First Response resources sufficient to remove $600 \mathrm{~m}^{3}$ in 36 hours at each primary Containment Site;

- Less than 24 hours for the deployment of a Full Tier 2 recovery capability of $3000 \mathrm{~m}^{3}$ to be in place within 24 hours; and

- A First Response less than 12 hours; in-place storage capacity of $360 \mathrm{~m}^{3}$ of which $25 \%$ will be handled by portable storage tanks and $33 \%$ by lined pits, and considering $40 \%$ losses between the pipeline and Containment Site plus a $100 \%$ emulsification factor, and the remaining material will be removed by tank truck or other means.

\subsection{Response to Marine Spills}

For the Marine Terminal, key elements of the response strategy include the response considerations listed above with the following additions:

- The strategy is focused on response to spills at the terminal and its surrounding waters;

- Spill containment and recovery at the loading terminal, including encirclement of part or the entire vessel by retention boom as necessary;

- Marine Oil Spill tracking system, $[5,7]$

- On water containment and recovery, utilizing a specially designed Oil Spill Response Vessel (OSRV), and tugboats outfitted with a boom and skimmer system;

- Open water containment; using open water boom to contain drifting oil to be collected by an on water skimming system;

- On water storage, using special barges to store recovered oil;

- Placement of equipment at designated Containment Sites to prevent the oiling of interior marine habitats;

- Shoreline protection, including the use of nearshore and shoreseal boom, filter fences and weir systems to prevent 
the contamination of sensitive interior waters and shoreline;

- Nearshore and shoreline recovery; to collect spilled oil using a variety of skimmers designed for different uses and oil types; and

- Shoreline cleanup; including the equipment and analysis of preferred methods to remove oil from all shoreline types present in the area.

The following time and spill volume recovery guidelines are used:

- Less than 12 hours for the deployment of First Response resources must be sufficient to remove $300 \mathrm{~m}^{3}$ in 48 hours at a single Containment Site;

- Less than 24-hours for the deployment of a Full Tier 2 recovery capability of $2200 \mathrm{~m}^{3}$ must be in place from two response depots within 24 hours.

The Operating Company will implement actions to cleanup oil released from its facilities to reasonable levels. No standards for determination of how-clean-is-clean for oil spills are known to exist in the area, or internationally. The Operating Company will work with the government, and others as appropriate, to establish guidelines and/or realistic target cleanup levels prior to emergency need.

\subsection{Response to NG and NGL Pipeline Accidents}

The Operating Company will establish equipment and response depots along the NG and NGL pipelines that are different than crude oil pipeline. Fire, flame, explosion, spilling and toxication [8 - 19] are the components of the accidents. The selection of locations of these response depots must be appropriate to the limits of the safety guidelines. These depots must be equipped fire and explosion safety equipment, modeling capabilities to establish fire and explosion safety zones [20 -22]. The rescue teams for fire and explosion must be established and the depots must be connected national and international centers that are in this nature. The response equipment list must be prepared by considering the specifications and terrain of the pipeline.

\section{Response Scenarios}

\subsection{Response Scenarios of Crude Oil Pipelines}

Response scenarios illustrate the manner in which the spill response may be undertaken, and these scenarios will be developed for use in training and drills exercises. The issues are:

Activation Guidance;

Containment Site location by KP (Kilometer Point);

Containment Sites ; and

Containment Site Reports and EM (Environmental Map) maps;

Equipments Available;

Potential Spill Quantity for Pipeline and Marine;

Spill Assessment and Tracking;

Response Depot and Time to Respond:

Rivers and Streams at the Spill Source;
River and Stream Velocities;

Sensitivity of Downstream Receptors;

Special Sensitive Areas at Spill Source;

Sources of Information Used in Scenario Development

Equipment Database; and

Notification Database and other related databases.

The following sample scenarios are selected:

Scenario 1 - Lubrication Oil Spill at Workshop in Pump Station PUMP-1, September;

Scenario 2 - Valve Leak at Pigging Station at Pump Station, July;

Scenario 3 - Pipeline Rupture KP 290, March; and

Scenario 4 - Large Release from Vessel Cargo Tanks, August.

Scenario 1 - Lubrication Oil Spill at Workshop in Pump Station PUMP-1, September.

\section{Situation Report:}

Lubrication oil drum falls from forklift while being moved; Location: KP 21.86;

Drum is righted but half spills inside the workshop;

Habitat type(s): Concrete floor and no oil leaves the workshop;

Probable Spill Size: 60 liters;

Month: September and

Oil Characteristics: Medium viscosity lubes oil.

Response Level:

Tier 1

Response Objectives:

Protect worker health and safety;

Stop the leak and repair the drum;

Stop the spread of oil;

Remove oil; and

Properly dispose of wastes.

Response Activity (by Hour)

0-1 hours:

Leak controlled. Sorbent boom and pads deployed from Tier 1 spill kit.

\section{1-2 hours:}

Cleanup continues with sorbents and rags.

2-3 hours:

Final oil removed by pressure wash. Oily waste collected.

3-4 hours:

Cleanup terminates.

Additional activities:

The Operating Company employs contractors for waste removal to certified landfills.

\section{Equipment:}

Tier 1 spill kits (local) and

Workshop employees use sorbents and PPE from the Tier 1 Spill Kits.

Scenario 2 - Valve Leak at Pigging Station at Pump Station PUMP-3, July

Situation Report:

Valve flange leak at pigging station at Pump Station PUMP-3; at KP 444.98 and 
Immediately brought under control, but oil sprayed over surrounding area.

Habitat type(s): Dirt, gravel, and paved road. No oil leaves the facility.

Probable Spill Size: $30 \mathrm{~m}^{3}$.

Month: July.

Oil Characteristics: Flowing, medium viscosity.

Response Level:

Initial Tier 1 - fully uses all material in Tier 1 Spill Kits and

Tier 2 - Activated.

Response Objectives:

Protect worker health and safety;

Stop the leak;

Prevent spread of oil into the environment;

Complete government and downstream industry notifications;

Remove pooled oil;

Remove contaminated soils and gravels;

Remove oil from hard surfaces and

Properly dispose of wastes.

Post Cleanup: Restore the area with clean material.

Response Activity (by hour)

0-1 hours: Leak controlled, Tier 1 cleanup initiated and

Response Contractor notified and prepares accordingly.

\section{1-2 hours:}

Response Contractor called out, departs equipment depots:

Tier 1 equipment exhausted.

2-3 hours:

Cleanup continues with shovels.

4-6 hours:

Response Contractor arrives (travel time 3 hours), deploys equipment,

Cleanup continues, use of sorbents, shovel cleanup, and bagging of oily material and

Hard surfaces cleaned with high-pressure washers.

7-8 hours:

Cleanup terminates.

Additional activities: The Operating Company contracts waste removal to certified landfills.

Equipment:

From PUMP-3: Tier 1 spill kits (local)

From Response Depot:

$8 \times 8$ response vehicle with front-end loader/backhoe;

$6 \times 6$ response vehicle with response trailer;

Vacuum Truck;

Skimmers; small weir and brush;

Pickup truck and $4 \times 4$ automobile.

Sorbents: pads and boom;

Shovels, gloves, and storage bags and

High-pressure washers.

From another Response Depot:

2 persons and

$8 \times 8$ response vehicle with roll-on, roll-off box.

Scenario 3 - Pipeline Rupture KP 290, March. Situation Report

Unknown loss at KP 290.0.
Potential size m3: 406-416 (leak), 2456-3556 (hole), 4589-6460 (rupture).

Later confirmed: $6,000 \mathrm{~m} 3$.

Sensitivity Categories: 10 - River and Stream. Otherwise open farm/grazing land.

River Crossings: $150 \mathrm{~m}$ from the River; 5-30 $\mathrm{m}$ wide.

River Velocity: $0.1 \mathrm{~m}$; low level, no ice.

Containment Site: AKIZ-08.

Environmental Map Number: EM\#33.

Month: March.

Oil Characteristics: Very slow flowing, high viscosity.

Response Level:

Initial Tier 1 - from PUMP-04 nearby;

Tier 2 - Activated immediately and

Tier 3 - Notified immediately; Equipment requested after review of the spill site.

Response Objectives:

Protect worker health and safety;

Stop the leak;

Complete government and downstream industry notifications;

Prevent spread of oil into the environment, particularly downstream in the stream/river;

Remove pooled oil;

Remove contaminated soils and

Properly dispose of wastes.

Post Cleanup: Restore the area with clean material.

Response Activity (by hour / days):

\section{0-1 hours:}

Leak observed;

Tier 1 cleanup initiated from adjacent PUMP-04;

Response Contractor called out;

Primary response depot (3.5 hours away) and Secondary response depot (3.9 hours away) activated and

Other equipment depots initiate backfill of equipment activated equipment depots.

\section{1-4 hours:}

Tier 1 equipment exhausted;

Leak controlled; estimated volume lost: $6000 \mathrm{~m}^{3}$;

Heavy equipment obtained from nearby government agency (from the Government Equipment Database) arrives on scene;

On site observers report oil has reached stream;

From Containment Site database and review of EM maps; $\mathrm{EM} \# 33$ and EM\#34; indicate that downstream sites are AKIZ-07, 06, and 03 and

Satellite phone communications directs the response depot to first setup in the furthest downstream (AKIZ-03) which is directly along their travel path. After setup at AKIZ-03, if no oil, they will move up to site AKIZ-06. The response team will go to AKIZ-07, 08 and then the spill site.

\section{4-10 hours:}

Response Contractors arrive;

Oil is near solid floating in cold water, stream levels are low;

Oil has not reached to AKIZ-07. Equipment is redeployed to AKIZ-07, 08 and the spill source and 
Lodging obtained in nearby city for Response Contractor workers (from Contacts Database).

Day 2-4:

Collection focuses on placement of filter fences, and use of viscous oil skimmers in the stream, and use of berms and dikes to stop oil movement at the source;

All viscous and brush skimmers obtained from all response depots $\left(128 \mathrm{~m}^{3} / \mathrm{hr}\right.$ capacity);

Tier 3 Contractor is instructed to supply additional skimmers, scheduled to arrive in 36 hours at nearby airport by regular air transport, airport and customs arrangements made and arrive in onscene by Day 4;

Collected oil is placed in lined storage pits dug with heavy machinery; and

Additional equipment contracted and obtained from government commercial agencies by using Contacts Database and Government Equipment Database.

Day 5-10:

Pooled oil operations completed.

Focus is on removal of contaminated sediments to temporary (lined) storage pits;

Specialists in bio-remediation are contracted; and

A rotation plan developed for Response Contractor personnel and supervisors, taking into account additional laborers obtained locally.

\section{Day 11-30:}

Many Response Contractor workers return to base. Supervisors and heavy equipment operators remain;

Land obtained for bioremediation; and

The Operating Company contracts for site restoration.

Day 30+:

Cleanup terminates;

Bioremediation, site restoration and monitoring begin; and Monitoring and bioremediation continue until complete.

\section{Equipment:}

Tier 1 spill kits (local) from PUMP-4;

Heavy Equipment and Transport Vehicles - from Response Depot as listed in the Contacts Database and Government Equipment Database.

From Response Depots:

$8 \times 8$ response vehicle with front-end loader/backhoe;

$6 \times 6$ response vehicle with response trailer;

Pickup truck and $4 \times 4$ automobile;

Portable storage tanks;

Plastic liner for storage pits;

Pumps and skimmers (weir, viscous and brush);

Sorbents: pads and boom;

Shovels, gloves, and storage bags;

Steam cleaners; and

Roll-on/roll-off boxes, accommodation module; and

Communications package.

From Other Depots:

Viscous and brush skimmers;

Filter fence kits;

Replacement equipment and personnel;

Additional laborers and transport obtained from nearby city, working with Government's office. All are given appropriate training by the Response Contractor; and

Near solid oil is transport in roll-on/roll off boxes to Marine Terminal for temporary storage and treatment.

Scenario 4. Large Release from Vessel Cargo Tanks, August.

Situation Report:

Unknown loss from vessel Marine Terminal, structural failure.

Potential size $\mathbf{m}^{3}:$ 1,000-10,000, duration 1-12 hours.

Later confirmed: $10,000 \mathrm{~m}^{3}$.

Sensitivity Categories: Marine waters; all shoreline sensitivities, recreational facilities.

Water Movement: $0.5 \mathrm{~m} / \mathrm{sec}$ southeast (1 knot).

Containment Sites: All sites 0 to $50 \mathrm{~km}$ to the south: AMCS-06, 07, 08, in and near Lagoon.

Environmental Map Number: EM\#53 to \#57 + Coastal Sensitivity Maps and Containment Manual + Nautical Chart of Area.

Month: August.

Oil Characteristics: Medium to light viscosities, increasing as the oil weathers.

Response Level:

Tier 2 -Activated immediately;

Tier 3 - Notified immediately, placed on standby alert.

Tier 3 - Later, activated to receive specific equipment.

Response Objectives:

Protect worker health and safety;

Stop the leak;

Complete government and downstream industry notifications;

Notify Coast Guard to close the area to fishing fleet;

Notify local governments to the south of potential impacts

to recreational beaches;

Prevent spread of oil on the water;

Protect Lagoonal shorelines;

Prepare for beach cleanup;

Clean contaminated shorelines;

Properly dispose of wastes; and

Post Cleanup: Evaluate and restore impacted areas.

\section{Response Activity (by hour / days)}

\section{0-1 hours:}

Leak observed. Loading operations stopped. Vessel undertakes actions to stop loss from cargo tank;

Response Contractor notified to activate all Response Depots; and

Tier 3 contractor notified and placed on standby. A close contact with government will be established during the incident.

\section{1-2 hours:}

Oil spill model trajectory shows oil movement to the south into open water, but with potential impact to south shore of Lagoon;

Open-water boom deployed from the harbor and towed by workboats and line-handling boats to surround the stricken vessel;

Oil Spill Response Vessel (OSRV) with onboard skimming 
system and recovery tank departs is coming to the accident area;

High-speed rubber boat deployed for oil spotting;

Large capacity brush skimmer placed on tugboat; and

Large capacity weir skimmer placed on another tugboat.

\section{2-6 hours:}

Tier 3 contractors instructed to deliver large skimmers, open-water boom, dracones for on-water storage, and transfer pumps, delivery is cleared for Airport in 24 hours, expected onscene in 30 hours;

The Response Contractor will handle local transport and expedite delivery, Customs Agency notified of incoming delivery, Tier 3 contractor supplies list of additional operators to be hired to operate the equipment;

Booming of the vessel completed, with approximately $30 \%$ of oil being retained;

On-water boom with the workboats successfully encircle large oil patches;

Using Contacts Database, large barge is contracted for on-water storage, arrival in 24 hours;

Oil recovery begins on water with the OSRV;

Storage barge units $\left(35 \mathrm{~m}^{3}\right)$ deployed in the water and pushed to work area by workboats;

OSRV is filled, and transfer begins to barge units. Barge units bring back oily water to small boat harbor; and

Vacuum trucks transfer barge cargo to the ballast water treatment.

\section{6-24 hours:}

Oil remains at sea;

On-water recovery operations continue at sea using two skimmer boats and three outfitted tugboats with storage;

Storage barges and tugs make $20 \mathrm{~km}$ roundtrip for offloading at the existing boat harbor;

Boom deployed at the designated Containment Sites;

On-water operations return at darkness, after risk analysis, pumping operations are allowed to continue at the Terminal under portable lighting; and

A night shift mans the Incident Command Center, planning for the next day's activities.

Day 2:

A wind shift pushes oil to south, sand-dominated shoreline of Lagoon; model results indicate impacts late on day 2,

Offshore operations continue using the two OSRVs, three tugboats, and four on-water storage barges;

Training of field crews for shoreline cleanup is completed;

Field teams from other Response Depots are sent to sand beaches south of to prepare for impacts by removing debris from the waterline;

Using Government Equipment Database, Government Agency agrees to send heavy equipment (road graders and front-end loaders to assist sand beach cleanup);

Oil impacts start on shoreline and into eroding marsh area of south side of Lagoon;

Shoreline cleanup concentrates on oil removal from the high-tide strand line using mainly manual labor working with the front-end loaders avoiding use of heavy machinery in oiled areas. As the tide drops, road graders effectively sweep oil and minimal sand into rows for removal by front-end loader. Sites are designated for the temporary storage of oily sand; and

At end of day, additional skimmers and equipment from Tier 3 contractor arrives, large barge storage also onsite.

Day 3:

On-water recovery is re-deployed taking advantage of the extra skimmers and storage capacity;

Shoreline cleanup continues, being directed by data provided by the Shoreline Cleanup Assessment Team (SCAT);

Marsh cleanup will start only after impacts end;

Oily sand is transported to a landsite for potential bioremediation of disposal;

Oil spill modeling indicates a likelihood of further impacts far to the southeast; and

Response teams are directed to activate containment sites AMCS-03, 04 and 05.

Day 4;

On-water operations recover decreasing amounts of oil, Wave conditions send most units to shelter;

New shoreline impacts occur near in the area;

Beach cleanup is divided into two groups: south of Lagoon, and in the nearby area, the latter concentrates on oil removal from recreational beaches; and

The Response Contractor supervises shoreline cleanup operations using newly trained workers, other staff and unneeded equipment return to their respective depot, marsh cleanup focused on removal of surface oil by hand laborers begins.

\section{Day 5 - 10:}

On-water operations are completed; Decontamination of equipment begins, Tier 3 material is returned to base;

Shoreline cleanup operations completed in the northern work area, a monitoring program of the area is developed. Workers shift to the south; and

Work in the south completes oil removal from sand beaches. Work on structures and bed rock area continues, contaminated sand is transported to an inland site for temporary storage or bioremediation, other contaminated material (sorbents, etc.) is sent to an approved landfills.

Day 11-30:

A termination of cleanup operations is approved with a monitoring program in place, and with the standby of additional response measures as needed;

A bioremediation plan is approved for treatment of oily sands, with a ground water monitoring program in place;

Response material is decontaminated or disposed; and

A SCAT assessment indicates restoration work is needed in recreational areas and in oiled marshes.

Day 30-45:

SCAT surveys continue on a weekly basis;

Response teams respond to additional intermittent oiling; and

Restoration work is undertaken by a hired contractor.

Day 45-60:

Operations terminate. 


\section{Equipment:}

All equipment from the Response Depot;

From other depots: fast flow and other skimmers, pressure washers, vehicles, storage boxes, vacuum trucks, PPE, etc.; and

Personnel from all response depots, keeping a basic staff in each response depot for abling to effectively respond to a new spill in their area.

Outside support: Heavy equipment from government agencies, storage barge from private supplier, Tier 3 skimmers, storage and boom.

Purchased equipment: additional spray and pressure washers, PPE, work clothes, storage bags, etc.;

Terminal support: workboats, line-handling boats, tugboats, oil-water separator and oily water transport;

Additional Laborers are given training and hired for shoreline cleanup facility at the existing terminal;

Tugboats setup two large skimmer systems around the terminal, and use pumps to lift oil to oily waste on the terminal for direct hard-line transfer to existing oil-water separator (capacity: $160 \mathrm{~m}^{3} / \mathrm{hr}$ );

After setup, tugboats redeploy for on water recovery using smaller disk and fast flow skimmers (capacity up to $30 \mathrm{~m}^{3} / \mathrm{hr}$ ); and

Boom and small skimmer systems sent to Containment Sites AMCS-07 and AMCS-08, incoming response team from other equipment depot is directed to cover AMCS-06 (deep within Lagoon).

\subsection{Response Scenarios for NG and NGL Pipelines}

A sample scenario is the following: Explosion at KP 220 is reported is reported.

\section{Scenario - Explosion and Fire at KP 220, September}

\section{Situation Report}

Explosion at KP 220 is reported.

Location: KP 220

Month: September.

Gas Characteristics: Natural Gas.

Response Level:

All levels.

\section{Response Objectives:}

Protect worker health and safety;

Stop the leak ;

Stop the fire; and

Rescue people if they are influence by fire, explosion and toxication.

\section{Response Activity (by Hour):}

\section{0-1 hours:}

Leak controlled;

Influenced area and communities are determined through modeling techniques;

Fire extinguishing starts;

\section{Later hours and days:}

Fire extinguishing continues;

Help for toxicated people continue; and
Wreckage cleanup continues.

Additional activities: The Operating Company contracts waste removal to certified landfill.

\section{Equipment:}

Fire engines;

Wreckage moving heavy equipment;

PPE and

Cleaning equipment

\section{Conclusions}

The paper presents an important issue of actions during the pipeline accidents. The material presented here is guidance for preparing planning, training and real time actions program for disaster situations. It should mentioned that each pipeline and its terrain have own particular specifications. The appropriate scenarios must prepare before the pipeline starts the operations. For optimum response, priory scenarios help the decision makers; it should be noted that probability of occurrence of a priory scenario is quite remote. However, the practice on priory scenarios will lead better actions by the operating company's management.

\section{Acknowledgements}

Thanks to Cihan Anul for discussions during progress of the paper.

\section{References}

[1] Huseyin Murat Cekirge, Outlines of an Oil Spill Response Plan (OSRP) for Crude Oil Pipelines, International Journal of Environmental Monitoring and Analysis. Vol. 3, No. 3, 2015, pp. 191-197. doi: 10.11648/j.ijema.20150303.21

[2] Huseyin Murat Cekirge, Omar K. M. Ouda, Ammar Elhassan, A Method for Preparing Environmental Social Impact Assessment (ESIA) of Crude Oil and Gas Pipelines, International Journal of Environmental Monitoring and Analysis. Vol. 3, No. 3, 2015, pp. 154-161. doi: 10.11648/j.ijema.20150303.17

[3] Huseyin Murat Cekirge, Environmental Risk Assessment Methodology (ERAM) for Oil Pollution, International Journal of Environmental Monitoring and Analysis. Vol. 3, No. 2, 2015 , pp. 91-110. doi: 10.11648/j.ijema.20150302.18

[4] Huseyin Murat Cekirge, Quantitative Risk Assessment for Crude Oil Pipelines, International Journal of Environmental Monitoring and Analysis. Vol. 3, No. 3, 2015, pp. 147-153. doi: 10.11648/j.ijema.20150303.16

[5] W. J. Lehr, R. J. Fraga, M. S. Belen, and H. M. Cekirge, "A New Technique to Estimate Initial Spill Size Using a Modified Fay-Type Spreading Formula," Marine Pollution Bulletin, 1 5(9), 326-329, 1984.

[6] W. J. Lehr, H. M. Cekirge, R. J. Fraga and M. S. Belen, "Empirical Studies of the Spreading of Oil Spills", Oil and Petrochemical Pollution, 2 (1), 7-11, 1984.

[7] H. M. Cekirge, "Oil Spills: Determination of Oil Spill Volumes Observed on Water Surfaces", The International Journal of Technology, Knowledge And Society, 8 (6), 17 - 30, 2013. 
[8] Huseyin Murat Cekirge, Qualitative Risk of Gas Pipelines, American Journal of Energy Engineering. Vol. 3, No. 3, 2015, pp. 53-56. doi: 10.11648/j.ajee.20150303.14.

[9] FEMA, Emergency Response Guidebook, 2008.

[10] FEMA, DOT, and EPA, Handbook of Chemical Hazards Analysis Procedures, US Environmental Protection Agency, US Department of Transportation, and the Federal Emergency Management Agency, 1989.

[11] United States Environmental Protection Agency (EPA), Evaluation of Dense Gas Simulation Models, Draft, EPA 450/4-90, United States Environmental Protection Agency, September 1990 .

[12] United States Environmental Protection Agency (EPA), Risk Management Program Guidance for Offsite Consequence Analysis (OCAG), EPA 550-B-99-009, United States Environmental Protection Agency, April 1999.

[13] United States Environmental Protection Agency (EPA), TANKS 4.09b, Computer Program, US Environmental Protection Agency, September 1999.

[14] United States Department of Transportation Office of Pipeline Safety (DOT-OPS), Gas Pipeline Incident Database, 1984-200 1, and Hazardous Liquid Incident Database, 1986-2001.

[15] United States Department of Transportation Office of Pipeline Safety (DOT-OPS), 2000 Annual Reports for Natural Gas Transmission and Distribution Pipeline Operators.

[16] United States Department of Transportation, Research and
Special Programs Administration, 49 CFR Part 192, [Docket No. RSPA00-7666; Amendment 192-95] RIN 2137-AD54, Pipeline Safety: Pipeline Integrity Management in High Consequence Areas (Gas Transmission Pipelines), ACTION: Final rule.

[17] U.S. Department of Commerce (US DOC), "Heat radiation from Large Pool Fires" NISTIR 6546, Fire Safety Engineering Division Building and Fire Research Laboratory, November 2000. Risk Assessment, American Institute of Chemical Engineers, New York, 1995.

[18] W. K, Muhlbauer, Pipeline Risk Management Manual, Second Edition, Gulf Publishing Co., Houston, TX, 1996.

[19] W. K, Muhlbauer, Pipeline Risk Management Manual, Third Edition, Gulf Publishing Co., Houston, TX, 2004.

[20] United States Environmental Protection Agency (EPA), ALOHA ${ }^{\circledR}$ Areal Locations of Hazardous Atmospheres, User's Manual, United States Environmental Protection Agency, Office of Emergency Management, Washington, D.C. and National Oceanic and Atmospheric Administration, Office of Response, Seattle, Washington, February 2006. United States Environmental Protection Agency (EPA), Download of ALOHA, Version 5.4, http:www.epa.Rov/ceppo/cameo/request.htm. Accessed September 2006.

[21] Mark W. Eltgroth, "CHARM ${ }^{\circledR}$ Emergency Response System Technical Reference Manual," Radian Corporation, September 1995.

[22] Radian International, CHARM® Technical Manual, 1995. 